\section{Effect of Coating Application on Chilling Injury of Grapefruit Cultivars}

\section{Huating Dou}

Florida Department of Citrus, 700 Experiment Station Road, Citrus Research and Education Center, Lake Alfred, FL 33850

Additional index words. postharvest handling, grapefruit, wax, temperature, storage, quality

Abstract. The effects of grapefruit cultivar and coating type on chilling injury (CI) incidence were examined. The shellac coating widely used for exported citrus resulted in the lowest CI incidence in white 'Marsh' grapefruit stored for 2 months at $4{ }^{\circ} \mathrm{C}$ and $92 \% \pm$ $3 \%$ relative humidity compared with nonwaxed fruit or fruit waxed with either carnauba or polyethylene waxes. The order of coating performance for reducing CI was shellac > carnauba $>$ polyethylene $>$ nonwaxed fruit. For 'Flame' little difference of coating type on CI was detected after 2 months of storage. Overall, CI incidence was high in fruit of the cultivars harvested from September to December, low in February, and high again after March but was generally higher in white 'Marsh' seedless grapefruit than 'Ruby Red', 'Rio Red', or 'Flame'. However, little difference of cultivar on CI incidence was found among the 'Ruby Red', 'Rio Red', and 'Flame' grapefruit except the October harvest in which CI was higher in 'Ruby Red' than in 'Rio Red'and 'Flame' grapefruit. These studies suggest that the coating and cultivar should be considered in the postharvest management of $\mathrm{CI}$ in commercial packing.

Chilling injury $(\mathrm{CI})$ of citrus is characterized by an initial collapse of peel tissue in discrete spots that become darkened, depressed, and sometimes appear in a circle form. In grapefruit, CI requires $\approx 4$ to 6 weeks to develop during cold storage (Grierson, 1986). Susceptibility of grapefruit to CI is closely related to the growth status of the tree, with fruit picked during a growth flush being particularly susceptible (Grierson, 1999; Kawada et al., 1978). Storage and/or shipment temperatures $<7.2^{\circ} \mathrm{C}$ can cause severe $\mathrm{CI}$, with the highest incidence occurring at $4.5^{\circ} \mathrm{C}$ (Hatton et al., 1981). Postharvest fungicides such as thiabendazole (TBZ) can reduce fruit susceptibility to chilling injury (Chalutz et al., 1985; McDonald et al., 1991; Schiffmann-Nadel et al., 1975). Intermittent weekly warming at $20{ }^{\circ} \mathrm{C}$ for $18 \mathrm{~h}$ prevented CI development in grapefruit stored at $2{ }^{\circ} \mathrm{C}$ (Cohen, 1999). In Florida, fruit are susceptible to CI in early (October to December) and late (March to May) seasons, but are more resistant during midseason (January to March) (Grierson, 1974, 1999; Purvis et al., 1979). However, the specific time of year when fruit become resistant to CI fluctuates with the growth status of the tree (Kawada et al., 1978). Fruit from the exterior canopy are reportedly more susceptible to CI than interior fruit and the sun-exposed side of a fruit is more susceptible to CI than the shaded side of the same fruit (McDonald et al., 1993).

Fresh citrus have traditionally been coated with waxes to increase fruit shine and to reduce weight loss (Hall, 1981). However, wax application can cause fruit off-flavor (Brown et al., 1998; Hagenmaier and Shaw, 1992) and

Received for publication 9 Apr. 2003. Accepted for publication 7 Oct. 2003. I thank Mr. Frank Kelsey, FMC, Lakeland, Florida, for the donation of waxes. Shelley Jones and Patricia Swingle were greatly appreciated for help with critical reading of this paper. the petroleum-based wax used in the 1980s. The objective of this study was to evaluate the effects of wax formulations on CI incidence and the CI susceptibility of major grapefruit cultivars grown in Florida.

\section{Materials and Methods}

Experiment I. Effect of shellac wax on CI development of white 'Marsh' grapefruit stored at four different chilling temperatures. Commercially harvested (21 Apr. 1999) white 'Marsh' grapefruit (Citrus paradisi Macf.) from the Indian River area of Florida were transported to the Citrus Research and Education Center (CREC), Lake Alfred, Fla., on the day of harvest. Fruit were not degreened or drenched. Fruit were stored at $21{ }^{\circ} \mathrm{C}$ and $92 \% \pm 3 \%$ relative humidity $(\mathrm{RH})$ overnight. On the second day, fruit were washed with sodium orthophenylphenate (SOPP, Freshgard 5, FMC Corporation, Lakeland, Fla.) and waxed with shellac coating (HS 590; FMC Corporation, Lakeland, Fla.). A nonwaxed treatment served as the control. No other fungicide was applied to the fruit. Fruit were then randomly packed in 16 different cartons. Each carton contained 33 fruit. Four cartons were randomly selected for each treatment and stored at $0.6,2,4$, and $7{ }^{\circ} \mathrm{C}$, and $92 \% \pm$ $3 \% \mathrm{RH}$ for $120 \mathrm{~d}$.

Experiment II. Effect of three major coatings on CI in white 'Marsh' and 'Flame' grapefruit. White 'Marsh' and 'Flame' grapefruit were received from the CREC groves, Lake Alfred, on 30 Nov. 2002. Fruit were washed with commercial fruit cleaner (Sooty Mold Clean 278; Decco, Monrovia, Calif.), dried at $45^{\circ} \mathrm{C}$ and waxed with carnauba (Sta-Fresh 921; FMC Corp., Lakeland, Fla.), shellac as described in Expt. I or polyethylene wax (Sta-Fresh 4201; FMC Corp.), respectively. A nonwaxed treatment of each cultivar was set up as a control. Treatments consisted of three replications of 25 fruit/replication. Fruit were examined for CI after 2 months of storage at $4{ }^{\circ} \mathrm{C}$ with $92 \% \pm 3 \% \mathrm{RH}$.

Experiment III. Effects of shellac and carnauba coatings on CI development in white 'Marsh' and 'Ruby Red' grapefruit. White 'Marsh' and 'Ruby Red' grapefruit were harvested on 6 Mar. 2000 in the Indian River area. After fruit were washed with SOPP, the grapefruit were commercially waxed with either carnauba or shellac waxes at a local packinghouse in Vero Beach, Fla. No other fungicide was applied. Fruit was transported to the CREC on the day of handling and stored at $4{ }^{\circ} \mathrm{C}$ with $92 \% \pm 3 \% \mathrm{RH}$. Each treatment included three replications consisting of 30 fruit per replication.

Experiment IV. Susceptibility of four grapefruit cultivars to CI. White 'Marsh', 'Flame', 'Rio Red', and 'Ruby Red' grapefruit were harvested on 23 Feb. 2001 in a grove in Lake Alfred. Fruit were washed and waxed as described previously in Expt. I. For each cultivar, three replicates of 33 fruit were used. Fruit were stored at $4{ }^{\circ} \mathrm{C}$ and $92 \% \pm$ $3 \%$ R.H.

Experiment V. Susceptibility of major grapefruit cultivars to CI during the season. Four cultivars of grapefruit (white 'Marsh', 
Table 1. Influence of various waxes on $\mathrm{CI}$ incidence, fruit weight loss, and fruit shine in 'Marsh' and 'Flame' grapefruit stored at $4{ }^{\circ} \mathrm{C}$ and $92 \% \pm 3 \%$ relative humidity for 2 months.

\begin{tabular}{lccc}
\hline Wax & $\begin{array}{c}\text { CI } \\
(\%)\end{array}$ & $\begin{array}{c}\text { Wt loss } \\
(\% / \mathrm{d})\end{array}$ & $\begin{array}{c}\text { Shine } \\
\text { (gloss unit) }\end{array}$ \\
\hline Marsh & $93 \mathrm{~d}^{2}$ & $0.103 \mathrm{~d}$ & $3.2 \mathrm{a}$ \\
$\quad$ Nonwax & $45 \mathrm{~b}$ & $0.083 \mathrm{bc}$ & $3.7 \mathrm{ab}$ \\
$\quad$ Carnauba & $22 \mathrm{ab}$ & $0.102 \mathrm{~d}$ & $6.2 \mathrm{c}$ \\
$\quad$ Shellac & $60 \mathrm{c}$ & $0.077 \mathrm{~b}$ & $3.4 \mathrm{a}$ \\
$\quad$ Polyethylene & & $0.099 \mathrm{c}$ & $4.5 \mathrm{~b}$ \\
Flame & $32 \mathrm{~b}$ & $0.057 \mathrm{a}$ & $3.1 \mathrm{a}$ \\
$\quad$ Nonwax & $11 \mathrm{a}$ & $0.071 \mathrm{~b}$ & $6.4 \mathrm{c}$ \\
$\quad$ Carnauba & $9 \mathrm{a}$ & $0.070 \mathrm{ab}$ & $4.1 \mathrm{ab}$ \\
$\quad$ Shellac & $9 \mathrm{a}$ & &
\end{tabular}

multiple range test at $P<0.05$.

'Ruby Red', 'Rio Red' and 'Flame') were tagged on 26 Sept. 2001 in Polk County. A total of 106 fruits were collected in plastic bushel crates at each harvest from each cultivar for transport to CREC, Lake Alfred, on the following dates: 26 Sept. and 16 Dec. 2001 and 30 Jan., 7 Mar., 11 Apr., and 7 June 2002. Fruit were hand picked equally from all sides of 16 trees, and included interior and exterior fruit. Fruit were held overnight at $22{ }^{\circ} \mathrm{C}$ and $92 \% \pm 3 \% \mathrm{RH}$ and packed the following day except that fruit from the 7 June 2002 harvest which were packed on 10 June. Harvested fruit were washed with SOPP and waxed with carnauba wax as described in Expt. II. Three replications of 30 fruit for each cultivar were boxed for storage at $4{ }^{\circ} \mathrm{C}$ and $92 \%$ to $96 \%$ RH. All fruit were packed in 35-L fiberboard cartons and stacked on wooden pallets. Fruit was examined for CI 3 months after storage at $4{ }^{\circ} \mathrm{C}$ with $92 \% \pm 3 \% \mathrm{RH}$.

Fruit evaluation. CI was rated by subjectively assigning each fruit a numerical rating of 0 (no damage), 1 (slight, $<5 \%$ of fruit surface damaged), 2 (moderate, $5 \%$ to $30 \%$ of fruit surface damaged), or 3 (severe, $30 \%$ to $100 \%$ of fruit surface damaged). Fruit scored greater than two (5\% to $30 \%$ of surface) for CI was used in calculating the percentage of fruit affected by the disorder for each replication.

Fruit shine. Fruit shine (gloss) was measured $60 \mathrm{~d}$ after wax application using a gloss meter (model Micro-Tri-gloss; BYK Gardner, Silver Springs, Md.). Ten fruit from each treatment were randomly selected. High values represent greater fruit shine (higher gloss) compared with low values that represent less shine.

Weight loss. Fruit weight loss was determined by weighing 10 fruit 0 and $60 \mathrm{~d}$ after wax application and was expressed as percent weight lost per day.

Statistics. Experimental data were statistically analyzed using Plotit (Scientific Programming Enterprises, Haslett, Mich.). Studies were conducted in completely randomized block design and data were analyzed using ANOVA. Means were separated using Duncan's multiple range tests at $P \leq 0.05$.

\section{Results}

Experiment I. Effect of shellac wax on CI severity of white 'Marsh' grapefruit stored at different chilling temperatures. Severe
CI developed in both waxed and nonwaxed 'Marsh' grapefruit stored at $4{ }^{\circ} \mathrm{C}$ or lower for $78 \mathrm{~d}$. In the nonwaxed fruit, the percentage of fruit with CI symptoms was $96,13,21$, and 1 at storage temperatures of $0.6,2,4$, and $7{ }^{\circ} \mathrm{C}$, respectively. The statistical analysis indicated that the $\mathrm{CI}$ incidence was higher at $0.6{ }^{\circ} \mathrm{C}$ than at $7{ }^{\circ} \mathrm{C}$. In the waxed fruit, the CI rate was $37 \%$ and $39 \%$ at 2 and $4{ }^{\circ} \mathrm{C}$, respectively, and only $11 \%$ for fruit stored below $1{ }^{\circ} \mathrm{C}$ and $3 \%$ for fruit stored at $7{ }^{\circ} \mathrm{C}$

Experiment II. Effect of three major coatings on CI in white 'Marsh' and 'Flame' grapefruit. After 2 months in storage, significant differences were found for fruit CI incidence, weight loss, and fruit shine. Generally, fruit CI incidence and fruit weight loss were higher in white 'Marsh' grapefruit than in 'Flame' grapefruit. All three waxes protected 'Flame' grapefruit from CI. In white 'Marsh' grapefruit, shellac wax provided better protection against CI among three waxes. The highest fruit shine was found in shellac-waxed fruit than fruit waxed with carnauba, polyethylene, or nonwaxed. Little difference in fruit shine was found among the fruit coated with either carnauba, polyethylene, or nonwaxed. Shellac wax greatly reduced CI in white 'Marsh' grapefruit while causing the lowest weight loss protection. Carnauba wax was the best wax to prevent fruit weight loss among the three waxes (Table 1).

Experiment III. Effects of shellac and carauba coatings on CI development in white 'Marsh'and 'Ruby Red'grapefruit. Shellac wax reduced CI development more than carnauba wax $(P<0.05)$. However, the magnitude of CI in fruit coated $\mathbf{C I}(\%)$

with shellac was still very high (13\% and 30\% in 'Rio Red' and 'Marsh' grapefruit, respectively). Ninety percent of 'Marsh' wax developed CI at day 100 after packing while only $30 \%$ of shellac waxed fruit developed CI. Again, this study confirms that 'Marsh' grapefruit are more susceptible to CI developmen than 'Ruby Red' grapefruit.

Experiment IV. Susceptibility offour grapefruit cultivars to $C I$. After 2 months of storage at $4{ }^{\circ} \mathrm{C}$ 'Flame' had less CI compared with 'Rio Red', 'Ruby Red', grapefruit coated with carnauba or 'Marsh' seedless grapefruit $(P<0.05)$. In the latter three cultivars, $23 \%$ to $32 \%$ of fruit developed CI while only $6 \%$ of 'Flame' grapefruit had CI symptoms. At the fourth month of storage, CI incidence increased in all four grapefruit cultivars; $54 \%$ to $58 \%$ of 'Marsh' seedless and 'Rio Red' developed severe CI, while lower CI was found in 'Flame' and 'Ruby Red' grapefruit (25\% to $31 \%$ ). 'Ruby Red' did not develop more CI during continued storage from 24 Apr. to 19 June 2001. Decay also increased with length of storage. Decay incidence was 5\% in 'Rio Red', $11 \%$ in 'Ruby Red', $18 \%$ in 'Flame', and $24 \%$ in white 'Marsh' grapefruit after 2 months of storage. After 4 months of storage, decay increased to $67 \%$ in 'Marsh' seedless grapefruit while decay rates of $15 \%$ to $24 \%$ occurred in the other three cultivars after 4 months of storage.

Experiment $V$. Susceptibility of major grapefruit cultivars to $C I$ during the fruit season. Little difference on CI was found among the 'Ruby Red', 'Rio Red' and 'Flame' grapefruit except from the October harvest in which CI incidence of 'Ruby Red' was higher than in 'Rio Red' and 'Flame' grapefruit. CI incidence was $\approx 90 \%$ in white 'Marsh' grapefruit from October to December, $20 \%$ to $40 \%$ in February to March, and 85\% in June 2002. Throughout the season, white 'Marsh' grapefruit developed consistently higher CI than the three colored cultivars used in this study. Among 'Rio Red', 'Flame', and 'Ruby Red', 'Ruby Red' seemed to be more susceptible to $\mathrm{CI}$ in early-season while little difference was found in the late-season harvest. The lowest incidence of CI developed in February fruit while the remaining harvests, particularly, the December harvest were more susceptible to CI development (Fig. 1).

Fig. 1. Percent CI after 3 months of storage at 4 ${ }^{\circ} \mathrm{C}$, and $92 \% \pm 3 \%$ relative humidity in majo grapefruit cultivars harvested during the fruit season 2001-02. Each treatment was repeated three times with 33 fruit. Unlike letters within each harvest date are significantly different according to Duncan's multiple range test at $P<$ 0.05 ; no 'Ruby Red' grapefruit was harvested after March 2002; no 'Rio Red' grapefruit was sampled in March 2002

HortScience Vol. 39(3) June 2004 


\section{Discussion}

Grapefruit handling at the packinghouse (washing, degreening, holding, etc.) reduces fruit resistance to $\mathrm{CI}$ because washing influences the fine wax structure of citrus peel (Petracek et al., 1998b), and furthermore, may affect flavedo tissue (Purvis, 1980). The application of wax creates a thin layer over the fruit surface. Microscopic examination reveals that shellac wax results in a continuous sheet of 2 to $15 \mu \mathrm{m}$ in thickness, while carnauba wax forms large particles with gaps over the fruit surface (Petracek et al., 1999, Tharanathan, 2003). The former wax provides in better protection of fruit from CI compared with carnauba wax. This may explain why the magnitude of CI reduction is greater in shellac-coated fruit than with carnauba. On the other hand, the thin protective layer created by shellac waxing limits fruit gas exchange, and furthermore influences fruit CI susceptibility (Hagenmaier and Shaw, 1992; Purvis, 1980). Thus, shellac wax reduces fruit internal oxygen concentration more than carnauba wax due to lower gas permeability (Hagenmaier and Shaw, 1992; Petracek et al., 1999). Therefore, postharvest pitting is more severe in shellacwaxed fruit and fruit deteriorate more quickly (Petracek, et al., 1998).

Grierson (1971) reported that waxing reduced CI in grapefruit but increased it in limes. However, wax formulations have dramatically changed in the last 2 decades (Petracek et al., 1999; Tharanathan, 2003). The exact chemical compounds in the wax formulations are unknown because wax vendors do not publish commercial wax ingredients. It is well know that shellac wax is a refined form of raw lac, a secretion of the lac bug while carnauba wax is excreted by the leaves of the palm (Copernica prunifera). Both are natural based waxes but the former is water-soluble; the latter is an emulsifiable wax (Grierson, 1986; Hagemmaier and Shaw, 1992; Hall, 1981; Tharanathan, 2003). The polymerizing ethylene gas obtained from petroleum gas manufactures polyethylene wax. This wax provides an intermediate fruit shine while giving moderate protection against weight loss and the development of oil gland breakdown (Petracek et al., 1999). Wax formulations are changing from year to year, from month to month, and from vendor to vendor. Frequently new surfactants and emulsifiers are used, replacing the old formulations (Tharanathan, 2003) Thus, all waxes used in this study are new waxes, and are different recipes from the waxes used in Florida citrus industry a half a decade ago. Our current and past studies confirm that the three waxes behave differently in fruit peel disorder development, flavor deterioration, fruit weight loss, fruit shine and fruit color changes (Brown et al., 1998; Dou et al., 1999a; Petracek et al., 1998). In this paper, fruit in all experiments were washed with SOPP and then waxed, indicating that SOPP is not a factor influencing the fruit $\mathrm{CI}$ in the current studies. In addition, the CI percentage was used because a CI score highe than $5 \%$ will indicate that the fruit's appearance is damaged and thus have an impact on the consumer's purchasing decision.
It is well known that shipping and storage temperatures are the most critical factors for minimizing fruit CI (Brown and Miller, 1999; Grierson, 1986). Schiffmann-Nadel et al. (1971) reported that CI was the lowest at 12 C among seven different storage temperatures in Israel. The lower the temperature, the higher the CI incidence if fruit was neither coated with commercial wax nor treated with fungicides. This explains why $\mathrm{CI}$ is much higher at 0.6 ${ }^{\circ} \mathrm{C}$ than at 2 to $4{ }^{\circ} \mathrm{C}$ (Expt. I). When Grierson (1971) stored fruit at $2.2^{\circ} \mathrm{C}$ for 0,7 , and 14 d, respectively, CI gradually increased with storage length. Since cold storage has been adopted in the Florida citrus industry in recent years, attention must be paid to evaluating CI in the 0 to $7{ }^{\circ} \mathrm{C}$ temperature range. In these studies, CI was much more severe at 2 and 4 ${ }^{\circ} \mathrm{C}$ in commercially packed/waxed grapefruit than that in fruit that were stored below $2{ }^{\circ} \mathrm{C}$ or above $4{ }^{\circ} \mathrm{C}$. Studies in the past suggested that grapefruit conditioned at $>10{ }^{\circ} \mathrm{C}$ for at least $7 \mathrm{~d}$ before storage had less $\mathrm{CI}$ than fruit stored continuously at $1{ }^{\circ} \mathrm{C}$ for $28 \mathrm{~d}$ or conditioned for only $2 \mathrm{~d}$ (Hatton et al., 1981). Dou and Ismail (2000) found that preconditioning at $7{ }^{\circ} \mathrm{C}$ was optimal for grapefruit because temperatures above $10{ }^{\circ} \mathrm{C}$ caused severe oil gland collapse known as postharvest pitting (Dou et al., 1999a; Petracek et al., 1998). Also, Dou and Ismail (2000) suggest that shipping and storage temperatures should be precisely controlled because the range between the optimal temperature and temperatures that increase $\mathrm{CI}$ incidence are very narrow. The optimal temperature of $7^{\circ} \mathrm{C}$ should minimize both pitting (oil gland collapse) and CI (Dou and Ismail, 2000)

Schirra et al. (1998) investigated grapefruit CI susceptibility in white and red cultivars such as 'Star Ruby' and 'Red Blush' in Mediterranean climatic conditions. The authors reported that 'Marsh' grapefruit were more susceptible to CI than 'Red Blush', 'Star Ruby', or 'Oroblanco' grapefruit. Results of current CI studies in four grapefruit cultivars are in agreement with the CI changes during the season in white 'Marsh' seedless grapefruit in the Floridian climate. The CI is lowest in midwinter but high in early or late season (Grierson, 1974; Kawada et al., 1978; Puvis et al., 1979). A positive correlation was found between resistance to CI and winter temperature higher than average indicated a possible benefit from preharvest stress (Kawada et al., 1978). The genetic and physiological differences among grapefruit cultivars are not well understood. The 'Flame' and 'Rio Red' are relatively new cultivars which were released in the late 1980s while White 'Marsh' and 'Ruby' grapefruit have been cultured since 1892 and 1929 , respectively. The new cultivars ('Rio Red', 'Flame') may be more tolerant of recent climactic and environmental changes, therefore, less susceptible to CI than white 'Marsh' grapefruit(Fig. 1). Weather conditions, nutrient management, and rootstocks influence CI susceptibility of grapefruit during the season and among the cultivars. Grierson (1986) reported that resistance to $\mathrm{CI}$ is correlated with peaks in abscisic acid (ABA). A recent study from Yuan et al. (2001) reported that the highest ABA concentration in 'Valencia' orange peel occurs in January to March while ABA concentration was low in November to December and again after mid-March. In line with the above results, Purvis et al. (1979) found that midwinter CI resistance correlates with the reducing sugars in grapefruit peel. A higher vitamin $\mathrm{C}$ and titratable acid concentration were found in white 'Marsh' grapefruit than in 'Rio Red', 'Flame', or 'Ruby Red' grapefruit (Dou, unpublished data). In addition lycopene, and $\beta$-carotene $\mathrm{C}$ concentration are also higher in 'Rio Red' than in 'Ruby Red' or 'Flame' grapefruit, possibly explaining why the CI incidence is consistently lower in ' $\mathrm{Rio}$ Red' grapefruit than other cultivars. However, no pigments (lycopene, and $\beta$-carotene) were found in white 'Marsh' grapefruit. These antioxidant profiles may play a role in the chilling susceptibility of grapefruit cultivars to CI. Ultimately, early season fruit (October to December) have immature peel, so that these compounds are not fully developed, while late season (April to June) fruit have decreased pigments, vitamin $\mathrm{C}$ concentrations, and low sugar to acid ratios (Dou, unpublished data) The hypothesis that CI development is closely correlated with the general fruit physiological life cycle or metabolism. Dou et al. (1999b) found a general decrease of fruit fluorescence in the late season fruit, which is consistent with the fruit hormone profiles during the season (Yuan et al., 2001)

These studies suggest that wax application reduces grapefruit CI development. Different wax formulations (shellac, polyethylene, or carnauba) result in different effect in controlling $\mathrm{CI}$ depending on grapefruit cultivar. When CI incidences are compared between the white 'Marsh' and 'Flame' grapefruit from this study, polyethylene was clearly less effective on 'Marsh' than 'Flame' grapefruit, and shellac more effective on 'Marsh' than 'Flame'. Generally, CI incidence was higher in white 'Marsh' seedless grapefruit than 'Ruby Red', 'Rio Red', and 'Flame' at most harvests throughout the fruit season. In commercial handling, particular attention should be given to 'Marsh' grapefruit because of its high postharvest susceptibility to CI and pitting (Table 1, Fig. 1) (Petracek et al., 1998). Packers might also consider cultivar when choosing wax coatings.

\section{Literature Cited}

Brown, G.E. and W.R. Miller. 1999. Maintaining fruit health after harvest, p. 175-188. In: L.W. Timmer and L.W. Duncan (eds.). Citrus Health Mgt., APS Press, St. Paul, Minn.

Brown, G.E., P.D. Petracek, M. Chambers, H Dou, and S. Pao. 1998. Attempts to extend the market availability of 'Marsh' grapefruit with storage at $2-3{ }^{\circ} \mathrm{C}$. Proc. Fla. State Hort. Soc. 111:268-273

Chalutz, E., J. Waks, and M. Schiffmann-Nadel 1985. Reducing susceptibility of grapefruit to chilling injury during cold treatment. HortScience 20:226-228.

Cohen, E. 1999. Current knowledge on storage of citrus fruit under intermittent warming, p. 93-106. In: M. Schirra (ed.). Advances in postharves diseases and disorders control of citrus fruit.

HortScience Vol. 39(3) June 2004 
Research Signpost, Trivandrum, India.

Dou, H. and M.A. Ismail. 2000. Effect of precooling and storage temperature on postharvest pitting incidence of citrus, p. 131-142. In:W.J. Florkowski, S.E. Prussia, and R.L. Shewfelt (eds.). Integrated view of fruit and vegetable quality. Technomic Publ. Co., Inc., Lancaster, Basel.

Dou, H., M.A. Ismail, and P.D. Petracek. 1999a. Reduction of postharvest pitting of citrus by changing wax components and their concentrations. Proc. Fla. State. Hort. Soc. 112:159-163.

Dou, H., M.A. Ismail, and P.D. Petracek. 1999b. Preliminary study on the relationship between fluorescence and pitting development of citrus. Proc. Fla. State. Hort. Soc. 112:163-166.

Grierson W. 1971. Chilling injury in tropical and subtropical fruits: IV. The role of packing and waxing in minimizing chilling injury of grapefruit. Proc. Trop. Reg. Amer. Soc. Hort. Sci. $15: 76-88$

Grierson, W. 1974. Chilling injury in tropical and subtropical fruits: Effect of harvesting date, degreening, delayed storage and peel color on chilling injury of grapefruit. Proc. Trop. Reg. Amer. Soc. Hort. Sci. 18:66-73.

Grierson, W. 1986. Physiological disorders, p. 361-378. In: W.F. Wardowski, S. Nagy, and W. Grierson (eds.). Fresh citrus fruits. AVI, New york.

Grierson, W. 1999. Role of temperature in the physiology of crop plants, p. 1-29. In: Pessarakli (ed.). Handbook of plant and crop physiology, 2nd ed. Marcel Dekker, New York.
Hagenmaier, R.D. and P. Shaw. 1992. Gas permeability of fruit coating waxes. J. Amer. Soc. Hort. Sci. 117:105-109.

Hall, D.J. 1981. Innovations in citrus waxing-An overview. Proc. Fla. State Hort. Soc. 94:258-263.

Hatton, T.T., P.L. Davis, R.H. Cubbedge, and K.A. Munroe. 1981. Temperature management and carbon dioxide treatments that reduce chilling injury in grapefruit stored at low temperatures. Proc. Intl. Soc. Citricult. 2:728-731.

Kawada, K. W. Grierson, and J. Soule. 1978. Seasonal resistance to chilling injury of 'Marsh' grapefruit as related to winter field temperature. Proc. Fla. State. Hort. Soc. 91:128-130.

McDonald, R.E., W.R. Miller, and T.G. McCollum. 1991. Thiabendazole and Imazalil applied at 53 ${ }^{\circ} \mathrm{C}$ reduce chilling injury and decay of grapefruit. HortScience 26:397-399.

McDonald, R.E., H.E. Nordby, and T.G. McCollum. 1993. Epicuticular wax morphology and composition are related to grapefruit chilling injury. HortScience 28:311-312.

Petracek, P.D., H. Dou, and S. Pao. 1998a. The influence of applied waxes on postharvest physiological behavior and pitting of grapefruit. Postharvest Biol. and Technol. 14:99-106.

Petracek, P.D., D.F. Kelsey, and C. Davis. 1998b. Response of citrus fruit to high-pressure washing. J. Amer. Soc. Hort. Sci. 123(4):661-667.

Petracek, P.D., R.D. Hagenmaier, and H. Dou. 1999. Waxing effects on citrus fruit physiology, $\mathrm{p}$ 71-92. In: M. Schirra (ed.). Advances in posthar- vest diseases and disorders control of citrus fruit. Research Signpost, Trivandrum, India.

Purvis, A.C. 1980. Respiration of grapefruit and orange flavedo tissue in relation to chilling injury and nonchilling temperatures and respiratory inhibitors. Proc. Amer. Soc. Hort. Sci. 105:209-213.

Purvis, A.C., K. Kawada, and W. Grierson. 1979. Relationship between midseason resistance to chilling injury and reducing sugar level in grapefruit peel. HortScience 14:227-229.

Schiffmann-Nadel M., F.S. Lattar, and J. Waks. 1971. The response of grapefruit to different storage temperatures. J. Amer. Soc. Hort. Sci. 96:87-90.

Schiffmann-Nadel M., E. Chalutz, J. Waks, and M. Dagan. 1975. Reduction of chilling injury in grapefruit by thiabendazole and benomyl during long-term storage. J. Amer. Soc. Hort. Sci. 100:270-272.

Schirra, M., M. Agabbio, and G. D'hallewin. 1998. Chilling responses of grapefruit as affected by cultivar and harvest date. Adv. Hort. Sci. 12:118-122.

Tharanathan, R.N. 2003. Biodegradable films and composite coatings: past, present and future. Trends Food Sci. Technol. 14:71-78.

Yuan, R., U. Hartmond, and W.J. Kender. 2001. Physiological factors affecting response of mature 'Valencia' orange fruit to CMN-Pyrazole. II. Endogenous concentrations of Indole-3-acetic acid, abscisic acid, and ethylene. J. Amer. Soc. Hort. Sci. 126:420-426. 